\title{
Richard BARLOW, The Celtic Unconscious. Joyce and Scottish Culture, Notre Dame, Indiana, University of Notre Dame Press, 2017
}

\section{Camille Manfredi}

\section{(2) OpenEdition}

\section{Journals}

\section{Édition électronique}

URL : http://journals.openedition.org/etudesirlandaises/5395

DOI : 10.4000/etudesirlandaises.5395

ISSN : 2259-8863

\section{Éditeur}

Presses universitaires de Caen

\section{Édition imprimée}

Date de publication : 29 novembre 2017

Pagination : 158-159

ISBN : 978-2-7535-7388-8

ISSN : 0183-973X

\section{Référence électronique}

Camille Manfredi, «Richard Bartow, The Celtic Unconscious. Joyce and Scottish Culture, Notre Dame, Indiana, University of Notre Dame Press, 2017 », Études irlandaises [En ligne], 42-2 | 2017, mis en ligne le 29 novembre 2017, consulté le 24 septembre 2020. URL : http://journals.openedition.org/ etudesirlandaises/5395; DOI : https://doi.org/10.4000/etudesirlandaises.5395

\section{(c) (i) (8)}

Études irlandaises est mise à disposition selon les termes de la Licence Creative Commons Attribution - Pas d'Utilisation Commerciale - Partage dans les Mêmes Conditions 4.0 International. 
Richard Barlow, The Celtic Unconscious. Joyce and Scottish Culture, Notre Dame, Indiana, University of Notre Dame Press, 2017, 328 p., ISBN 978-0-26810101-5, \$50.

Enseignant-chercheur à l'Université de Nanyang à Singapour, Richard Barlow, spécialiste en études croisées irlando-écossaises, propose dans The Celtic Unconscious une approche inédite de l'influence qu'eut l'Ecosse sur l'écriture de James Joyce, et en particulier sur celle de Finnegans Wake. Objet de trop rares investigations critiques, la présence écossaise dans l'œuvre et la pensée de Joyce est ici abordée par le biais de micro-analyses et d'exercices de contextualisation tout à fait convaincants.

On pourra estimer malheureux le choix d'un titre fleurant d'emblée l'essentialisme culturel et pouvant sembler dissuasif à certains ; ces réserves sont pourtant vite dissipées, puisque dès l'introduction, Richard Barlow annonce envisager cet "inconscient celtique " comme une construction identitaire émanant d'un auteur dévoué à la dés-anglicisation de l'Irlande, de sa culture et - surtout, car c'est le propos de l'ouvrage - de ses paradoxes. Le celticisme joycien est ainsi pensé comme principalement non-anglais, autorisant dès lors une réévaluation des échanges culturels entre Ecosse et Irlande comme révélateurs d'un " esprit celtique " susceptible de ménager les diversités ethniques et linguistiques des deux nations. Pas plus que Joyce Barlow ne propose une vision unifiée, panceltique et simpliste d'un ethos irlando-écossais il ne propose de clé vers une communauté imaginaire qui serait stable et normalisante.

Ulysses et Finnegans Wake sont approchés comme les réponses de Joyce à l'impérialisme britannique sous l'angle d'une " esthétique ethno-philosophique " (p. 9) empruntée à David Hume. Le dialogue entre scepticisme et idéalisme initié par le philosophe édimbourgeois sert alors de modèle pour détecter les dynamiques concurrentes qui animent l'œuvre de Joyce et que Barlow rapproche de la théorie de la "Caledonian antisyzygy " exposée par G. Gregory Smith dans Scottish Literature: Character and Influence en 1919, une théorie par ailleurs fréquemment convoquée par les critiques de Robert Louis Stevenson et James Hogg. Image d'une réaction au matérialisme anglais, concession toute " celte " (nous dit Joyce) à l'inconnu, l'inconscient devient alors une construction culturelle en soi, proche de l'Autre de Fredric Jameson, cette part cachée d'un environnement culturel qui n'affleure que dans le rêve ou dans la confrontation et union des contraires que « symbolise » (p. 34) l'Écosse.

Le premier chapitre se penche sur le personnage de Crotthers dans Ulysses que Barlow nous présente comme un passeur, figure de la liminalité et incarnation des flux entre Ecosse et Irlande, mais aussi entre dominants et dominés. Suivent deux chapitres qui explorent plus avant l'influence de la pensée de Hume sur l'œuvre 
de Joyce et son rejet du matérialisme historique au profit d'une approche psychomorphe de l'Histoire. Le chapitre 4 approfondit l'idée d'une celticité joycienne conçue comme un "état inconscient » (p.150) et une porte d'entrée vers l'inquiétante étrangeté. Le chapitre suivant, peut-être plus convaincant, se penche sur l'intérêt de Joyce pour le bricolage et le recyclage interculturels de James Macpherson. Ainsi, selon Barlow, "[i]f Macpherson's work was an effort to construct a memorial for an endangered civilization in the face of modernity and imperialism. Finnegans Wake replicates the attempt to create a spectral "memory", an inner Celtic state as an alternative to materialism" (p. 158). Le chapitre conclusif est quant à lui dévoué à l'empreinte de Robert Burns et envisage enfin l'influence de Joyce sur les poètes et romanciers écossais du vingtième siècle - dont bien sûr Hugh MacDiarmid.

The Celtic Unconscious a le grand mérite de lever le voile sur une part de l'œuvre joycienne jusqu'ici peu explorée. Si le modèle de la "Caledonian antisyzygy " est désormais contesté, il est sollicité avec précaution et à bon escient, systématiquement appuyé sur des exemples concrets tirés des deux romans principalement abordés, Finnegans Wake et Ulysses. L'ouvrage témoigne d'une originalité et d'une rigueur scientifique qui saura satisfaire autant les spécialistes de Joyce que les irlandistes et scotticistes qui trouveront là, à n'en pas douter et probablement dès le paratexte, matière à débat.

Camille MANFredi

Marie Mianowski, Post-Celtic Tiger Landscapes in Irish Fiction, London, Routledge, 2017, 186 p., ISBN 978-1-4724-8798-8, £110.00 (hardcover).

Dans cet ouvrage, Marie Mianowski invite à une lecture de la littérature irlandaise ultra-contemporaine à travers le prisme de l'espace, du lieu et du paysage. Au premier abord, ces thèmes ne surprendront pas quiconque est familier du contexte irlandais tant la terre, sa possession, sa perte et son contrôle ont joué un rôle majeur dans l'histoire politique, sociale et culturelle du pays. Seamus Heaney avait déjà conceptualisé l'importance du lieu dans l'imaginaire collectif irlandais dans son célèbre texte "A Sense of Place ». Pourtant cette approche semble particulièrement appropriée à l'époque envisagée dans l'ouvrage, celle qui suit l'effondrement de l'économie du Tigre celtique, fondée en partie sur la spéculation immobilière. Ainsi les modifications profondes de la société irlandaise se sont trouvées reflétées par les transformations du paysage urbain ou rural, ce que la littérature a enregistré à son tour, à tel point que la fiction irlandaise des années $2010 \mathrm{a}$ pu donner les signes d'une véritable obsession pour les chantiers de construction, les terrains, les friches 